\title{
Long Range Electron Transfer Quenching in Polyamine Chains Bearing a Terminal Naphthalene Unit
}

 \\ M. Teresa Albelda, ${ }^{\S}$ and Enrique García-España* $* \S$
}

REQUIMTE/CQFB, Departamento de Química, Faculdade de Ciências e Tecnologia, Universidade Nova de Lisboa, Quinta da Torre, 2825 Monte de Caparica, Portugal, Departamento de Química (CQC), Faculdade de Ciências e Tecnologia, Universidade de Coimbra, 3004-535 Coimbra, Portugal, and Departament de Química Inorgànica, Facultt de Química, Universitat de València, Spain, C/ Dr. Moliner 50, 46100 Burjassot (València), Spain

Received: March 28, 2002; In Final Form: May 29, 2002

\begin{abstract}
The fluorescence emission of a naphthalene unit attached to a polyamine chain is quenched by intramolecular electron transfer from the deprotonated amines to the excited fluorophore. Measurements of the respective quenching rate constants as a function of the distance, reveal an exponential dependence with $\beta=0.45 \AA^{-1}$. Identical measurements carried out in deuterated water have shown a similar dependence with the distance $\beta=0.49 \AA^{-1}$ but an average reduction of the absolute values of the rate constants of ca. 1.2. The polyamine chains seem to constitute a bridge through which the electron can find a route to its movement, more efficiently than through space.
\end{abstract}

\section{Introduction}

Electron-transfer processes play a crucial role in biological systems such as the respiratory chain and photosynthetic process. ${ }^{1-4}$ Sequences of thermal and/or photoinduced electrontransfer steps allow electron transfer from donor to acceptor units localized at distances exceeding the sum of their respective van der Waals radii. This is exemplified by the long-range electron-transfer process taking place in proteins at distances from 10 to $30 \AA$. Mimetic systems for these natural process are covalently linked donor/acceptor molecules (CLDA), and by consequence, hundreds of organic and inorganic CLDA systems have been reported in the literature. ${ }^{1}$ Of particular interest is the work of Gloss and co-workers who have experimentally verified the Marcus inverted region with a system consisting of biphenyl and naphthalene units linked through a steroid type bridge. ${ }^{5-7}$

In previous work, carried out in systems containing a polyamine chain bearing a terminal aromatic fluorophore, we have shown that the most intense emission occurs for the fully protonated form and that proton abstraction from the polyaminic chain leads to a decrease in the emission intensity. ${ }^{8-11}$ This quenching effect is due to the intramolecular electron transfer process involving the lone pair of a deprotonated amine and the excited fluorophore. Moreover, it was also observed that the degree of quenching shows a crucial dependence, not only with the chain length but also with the stage of protonation.

This work makes relevance to the distance dependence of the quenching rate constants in polyamine chains bearing a terminal naphthalene unit and to the effect of isotope substitution (proton by deuterium), on both the quenching rate constants $\left(k_{\mathrm{q}}\right)$ and distance dependence $(\beta)$.

* To whom correspondence should be addressed. E-mail: enrique.garcia-es@uv.es.E-mail: fjp@dq.fct.unl.pt.E-mail: sseixas@ci.uc.pt.

$\dagger$ Universidade Nova de Lisboa.

¥ Universidade de Coimbra.

$\S$ Universitat de València.

\section{Experimental Section}

Materials. Ligands $\mathbf{I}-\mathbf{V}$ were synthesized as previously described ${ }^{12}$ and handled as their hydrochloride salts. $\mathrm{D}_{2} \mathrm{O}$ and $\mathrm{H}_{2} \mathrm{O}$-milliQ were used as solvents in the spectrophotometric and spectrofluorimetric titrations.

emf Measurements. The potentiometric titrations were carried out at $298.1 \pm 0.1 \mathrm{~K}$ in $\mathrm{NaCl} 0.15 \mathrm{~mol} \mathrm{dm}^{-3}$. The experimental procedure (buret, potentiometer, cell, stirrer, microcomputer, etc.) has been fully described elsewhere. ${ }^{12}$ The acquisition of the emf data was performed with the computer program PASAT. ${ }^{13}$ The reference electrode was an $\mathrm{Ag} / \mathrm{AgCl}$ electrode in saturated $\mathrm{KCl}$ solution. The glass electrode was calibrated as an hydrogen-ion concentration probe by titration of previously standardized amounts of $\mathrm{HCl}$ with $\mathrm{CO}_{2}$-free $\mathrm{NaOH}$ solutions and determining the equivalent point by the Gran's method, ${ }^{14}$ which gives the standard potential, $E^{\circ}$, and the ionic product of water $\left(\mathrm{p} K_{\mathrm{w}}=13.73(1)\right) . \mathrm{NaCl}$ was used as the supporting electrolyte instead of the most usual $\mathrm{NaClO}_{4}$ because of the slightly higher solubility of the receptors in this medium.

The computer program HYPERQUAD ${ }^{15}$ was used to calculate the protonation and stability constants. The titration curves for each system (ca. 100 experimental points corresponding to at least three measurements, $\mathrm{pH}$ range investigated $2-10$, concentration of metals and $\mathrm{L}$ ranging from $1 \times 10^{-3}$ to $5 \times 10^{-3}$ mol $\mathrm{dm}^{-3}$ ) were treated either as a single set or as separated curves without significant variations in the values of the stability constants. Finally, the sets of data were merged together and treated simultaneously to give the final stability constants.

NMR Measurements. The ${ }^{1} \mathrm{H}$ and ${ }^{13} \mathrm{C}$ NMR spectra were recorded on Varian UNITY 300 and UNITY 400 spectrometers, operating at 299.95 and $399.95 \mathrm{MHz}$ for ${ }^{1} \mathrm{H}$ and at 75.43 and $100.58 \mathrm{MHz}$ for ${ }^{13} \mathrm{C}$. The spectra were obtained at room temperature in $\mathrm{D}_{2} \mathrm{O}$ or $\mathrm{CDCl}_{3}$ solutions. For the ${ }^{13} \mathrm{C}$ NMR spectra, dioxane was used as a reference standard $(\delta=67.4$ 


\section{SCHEME 1}
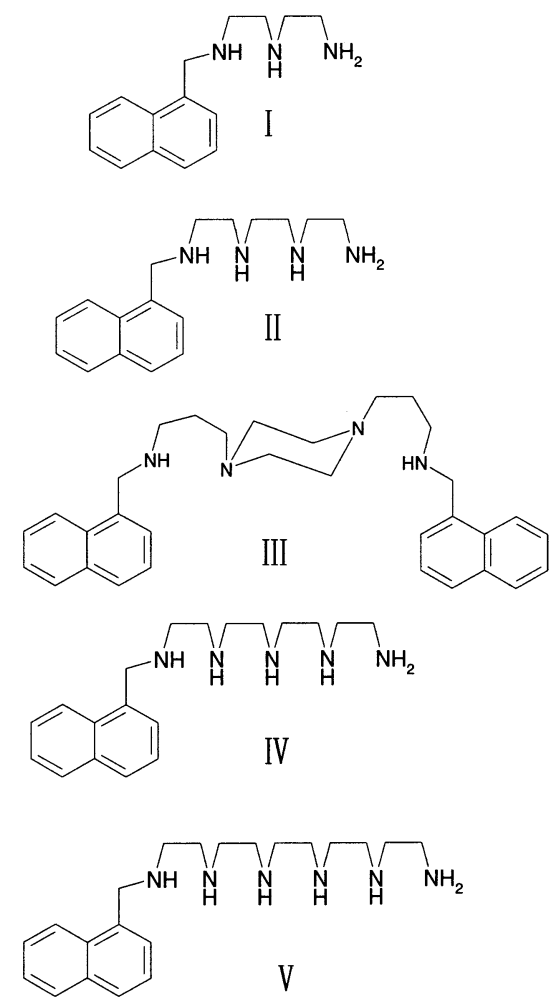

ppm) and for the ${ }^{1} \mathrm{H}$ spectra the solvent signal. A variable temperature accessory regulated the probe temperature. Adjustments to the desired $\mathrm{pH}$ were made using drops of $\mathrm{DCl}$ or $\mathrm{NaOD}$ solutions The $\mathrm{pH}$ was calculated from the measured $\mathrm{pD}$ values using the correlation, $\mathrm{pH}=\mathrm{pD}-0.4{ }^{16}$

Spectrophotometric and Spectrofluorimetric Titrations. Absorption spectra were recorded on a Shimadzu UV-2510 PC, UV-vis recording spectrophotometer, and fluorescence emission was recorded on SPEX F111 Fluorolog spectrofluorimeter. $\mathrm{HCl}$ and $\mathrm{NaOH}$ were used to adjust the $\mathrm{pH}$ values that were measured on a Metrohm $713 \mathrm{pH}$ meter. All of the measurements were carried out in $0.15 \mathrm{~mol} \mathrm{dm}^{-3} \mathrm{NaCl}$. Linearity for the fluorescence emission was checked in the concentration range used. The absorbance of the excitation wavelength was maintained lower than ca. 0.15. When excitation was carried out at wavelengths different from the isobestic points, a correction for the absorbed light was performed.

Fluorescence lifetimes were measured by time correlated single photon counting technique (TCSPC) as described elsewhere. ${ }^{17}$ The fluorescence decays were analyzed using the method of modulating functions implemented by Striker with automatic correction for the photomultiplier "wavelength shift". ${ }^{18}$ All measurements were made in the presence of oxygen to reproduce the conditions where steady-state fluorescence data was obtained.

\section{Results and Discussion}

The fluorescence intensity dependence with the hydrogenionic concentration, for compounds $\mathbf{I}-\mathbf{V}$ (Scheme 1), is presented in Figure 1. The most intense emission occurs for the fully protonated form, and the subsequent proton removal (from the chain) leads to a decrease in the emission intensity. ${ }^{9-11}$ This quenching effect is due to an intramolecular electron-transfer process involving the lone pair of a deprotonated amine.

The electron-transfer quenching rate constant, $k_{\mathrm{q}}$, for each species can be obtained from the Stern-Volmer equation, modified according to intramolecular processes, $\left(I_{0} / I=1+k_{\mathrm{q}} \tau_{0}\right)$ where $I_{0}$ and $\tau_{0}$ are respectively the emission intensity and lifetime of the unquenched species (fully protonated form, $\tau_{0}$ $=24 \mathrm{~ns}$ in aerated solutions) and $I$ is the emission intensity of the species suffering quenching (deprotonated species). The plot of the quenching rate constants obtained upon removal of a single proton in compounds $\mathbf{I}-\mathbf{V}$ vs a quantity proportional to the chain length (the bond distance between the fluorophore and the virtual middle point of the polyamine chain) are presented in Figure 2 (filled circles). An exponential dependency is clearly observed and can be further correlated with our knowledge about the deprotonation pattern presented by these compounds.

The middle point distance, as defined above, has a particular and critical meaning in these systems. The $\mathrm{pH}$ dependence of these compounds is mainly determined by electrostatic repulsion, which rules the proton distribution in the chains; that is, protons choose to be as far apart as possible. The average protonation sequence can be inferred from the shifts that the ${ }^{13} \mathrm{C}$ and ${ }^{1} \mathrm{H}$ NMR resonances undergo with the $\mathrm{pH}$. In particular, the carbon nuclei placed in $\beta$ position and the hydrogen atoms bound to the carbons in $\alpha$ with respect to the nitrogen atoms bearing deprotonation move significantly downfield and upfield, respectively. In Figure 3, as an example, we present the aliphatic region of the ${ }^{13} \mathrm{C}$ NMR spectra of compound $\mathbf{I}$ recorded at several significant $\mathrm{pH}$ values.

In this compound, the chemical shifts of the carbon atoms labeled as $\mathrm{C} 2$ and $\mathrm{C} 5$ placed in the $\beta$ position with respect to the central nitrogen atom shift markedly downfield on going from $\mathrm{pH} 2$ to 5 in correspondence with the first deprotonation step of the ligand (Figure 1). The same observation can be made for carbon atom 4 above $\mathrm{pH} 8.5$ where the last deprotonation occurs suggesting that the first proton attaches mainly to the primary amino group at the end of the chain. However, it has be to be stressed that although this NMR change denotes the presence of majoritary species in solution it does not discard the presence of other prototropic isomers whose relative amounts must be thermodynamically controlled.

Thus, the first deprotonation of $\mathbf{I}$ affects mainly the central nitrogen, and this is valid for all cases where the chain consists of an odd number of nitrogens (e.g., compounds I and IV). In the cases where the chain has an even number of nitrogens (compounds II, III, and V), the first deprotonation affects mainly the methylenic groups, connected to the two central nitrogens, and because symmetry is preserved, the interpretation is that deprotonation leads to a species where these two nitrogens share a single proton, or alternatively, each nitrogen is protonated "half of the time". In summary, in all cases, the first deprotonation occurs with the proton in the middle of the chain but with two different outcomes: one unprotonated nitrogen in the case of odd numbers and two-half protonated nitrogens in the case of even numbers.

The distance $(d)$ in Figure 2 was obtained from a direct measurement of the bond lengths in a space-filling model. This was taken from the distance of the naphthalene carbon atom $\mathrm{C}(1)$ to the deprotonated nitrogen and is consequently independent of any conformational assumption. For species Ia and IVa, see Figure 4 (the sufixes a, b, and c stand for first, second, and third deprotonation respectively), it is likely to consider that the most probable proton distribution results from the central nitrogen proton free (see above).

In the case of species IIa, IIIa, and Va, in Figure 4, the proton should be equally shared between the two central nitrogens. At this stage, a model where the two central nitrogens are 

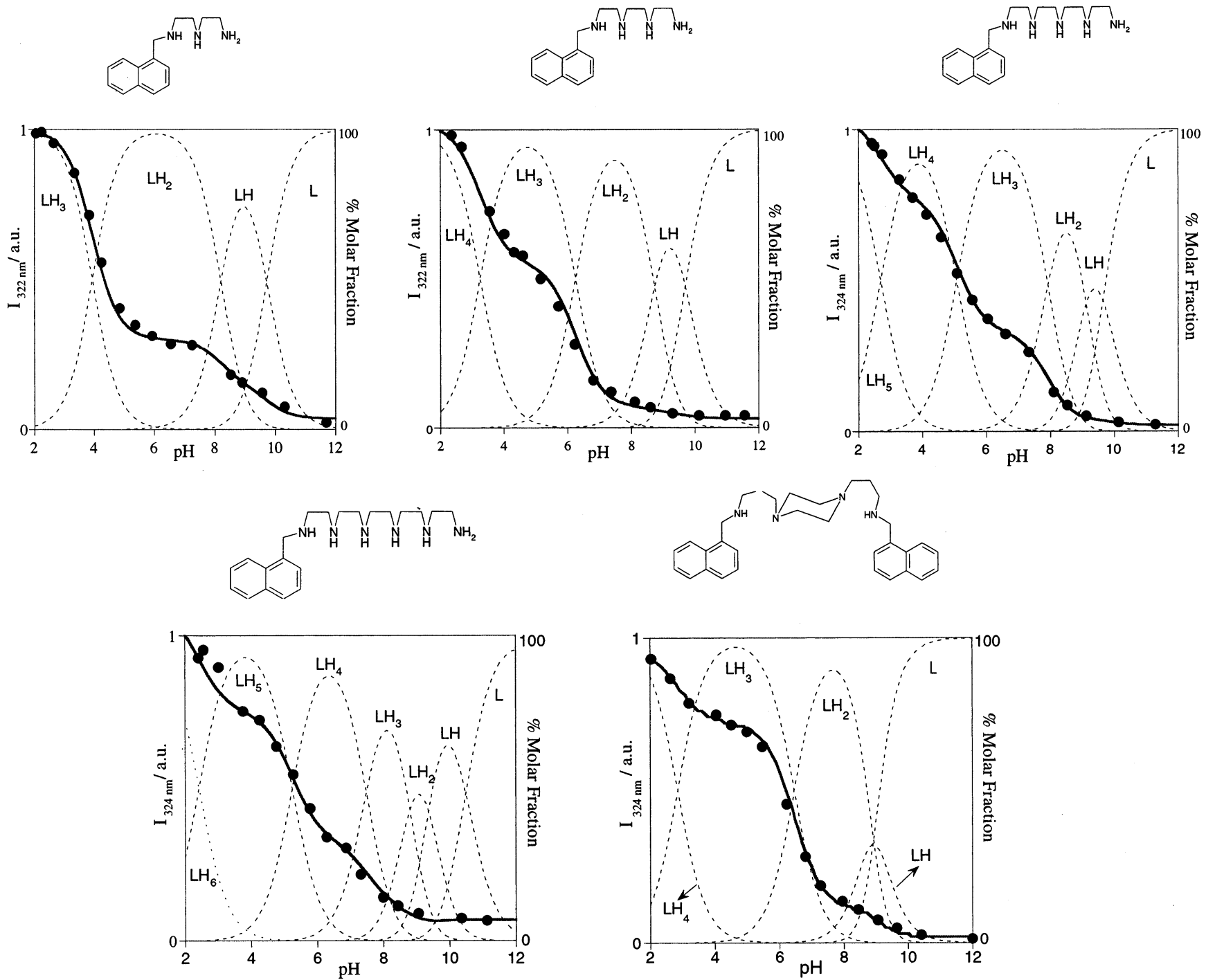

Figure 1. Fluorescence titration curves of compounds $\mathbf{I}-\mathbf{V}$. The data points are normalized to the fluorescence of the fully protonated form $\left(I / I_{0}\right)$. Molar fractions of the species are also plotted and were calculated from potentiometric constants.

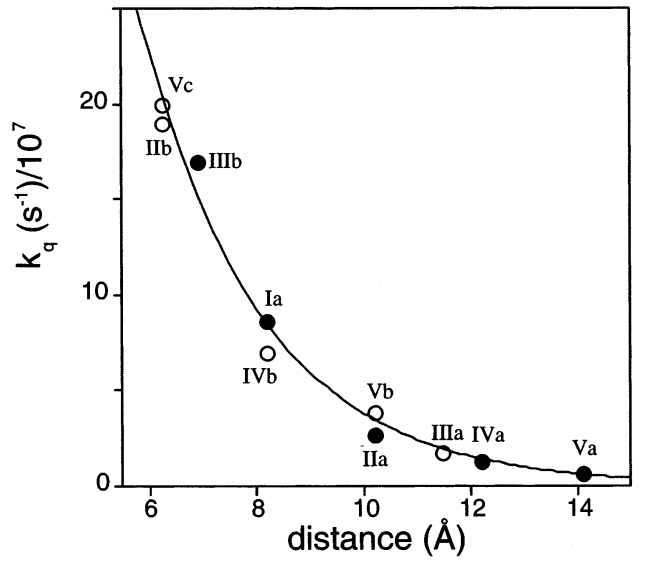

Figure 2. Exponential dependence of the quenching rate constants with the distance in water. Closed circles, monodeprotonated species; open circles, dideprotonated (and trideprotonated) species.

protonated only one-half of the time can be equated. In that case, we would have, for example, with species IIa, a quenching rate constant equal to the semisum of the quenching constants for species Ia and IVa (see Figure 2), i.e., $0.5 \times 10^{8} \mathrm{~s}^{-1}$. This value is quite different from the observed value of $0.26 \times 10^{8}$ $\mathrm{s}^{-1}$. Actually, what we observe is that the quenching rate constant for species IIa falls off, according to a general exponential dependence with the distance, if the mean distance between the second and third nitrogen atoms is considered (counting the nitrogens from left to right).

This procedure was extended to the compounds whose quenching rate constants result from a second deprotonation (and third deprotonation for the species bearing the largest chain), Figure 2, opened circles, and Figure 4. In the cases where two protons have been removed, the observed quenching rate constant, $k_{\text {obs }}$, will result from the sum of two parcels: (i) the quenching due to the first deprotonated nitrogen $\left(k_{\mathrm{q}}\right.$, previously calculated) plus (ii) the quenching from the second deprotonated nitrogen (rate constant $k_{\mathrm{q}}^{\prime}$ ). In the case of species Vc (see Figure 4), a third quenching rate constant was calculated mutatis mutandis.

The protonation sequences, here shown for the second and third deprotonation, are not only supported by the exponential dependence but also from our previous work. ${ }^{9-11}$ In particular, we have observed from NMR studies, taken with the compounds here reported and also with similar systems, containing anthracene (or benzene) as the emissive chromophore instead of naphthalene, that the first proton release always takes place with the central nitrogens. ${ }^{8-11}$ On the other hand, the protonation sequence is mainly ruled by the existence of a minimum of 

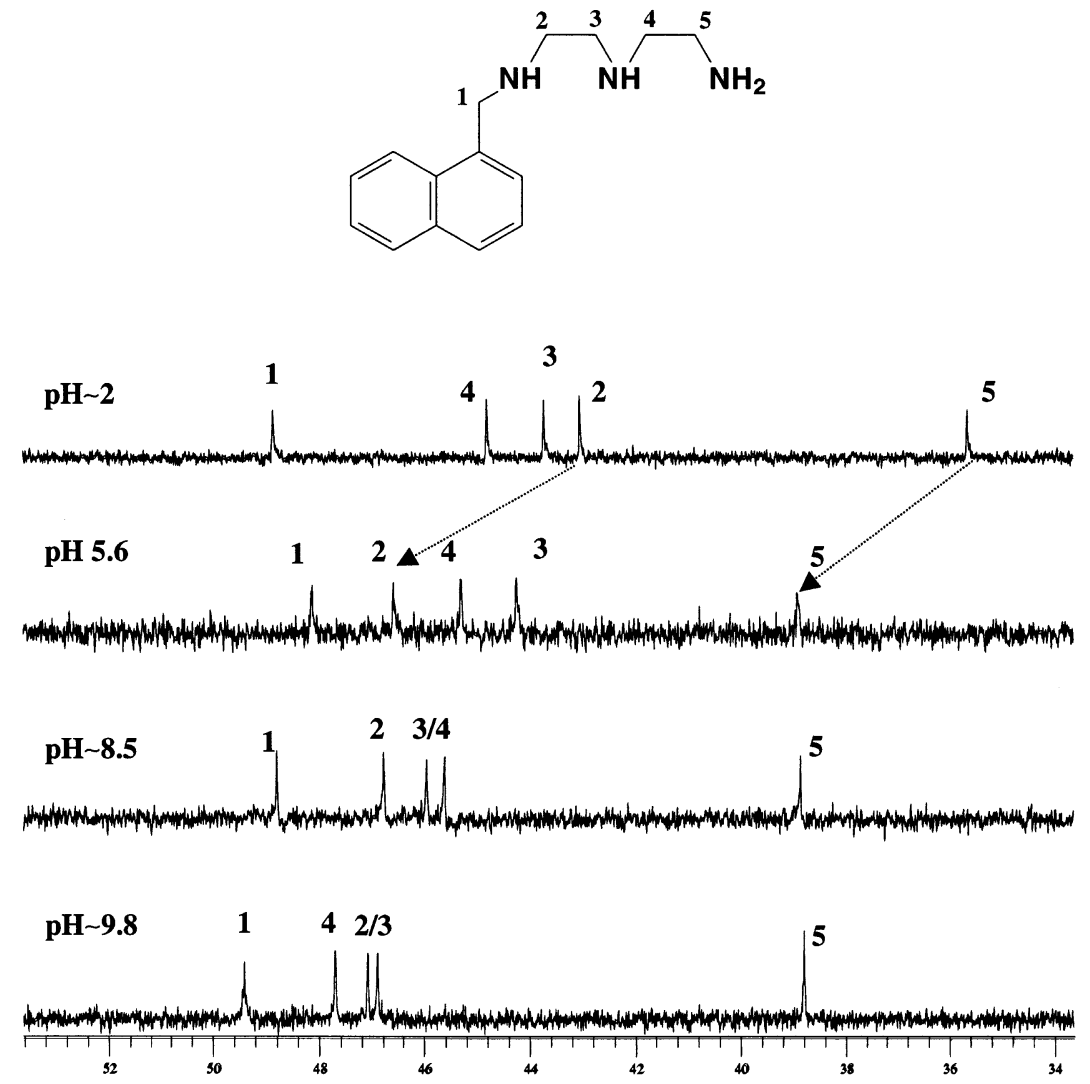

Figure 3. ${ }^{13} \mathrm{C}$ NMR spectra of compound I recorded at different $\mathrm{pH}$ values. Representation of the ${ }^{13} \mathrm{C}$ chemical shifts of the aliphatic carbon atoms as a function of $\mathrm{pH}$.

repulsion between equally charged species. The obtained exponential dependence for the quenching rate constant, shown in Figure 2, is of general formula, $k_{\mathrm{q}}=k_{\mathrm{q}}(0) \exp (-\beta d)$, leading to a $\beta$ factor of $0.45 \AA^{-1},{ }^{1-7}$ suggesting that electron transfer would occur at longer distances than expected for an aliphatic system.

At this point, a mention of the nonrigidity of these systems and its consequences must be made. In fact, in the present case, the strict sense of fixed donor acceptor distances cannot apply, perhaps with the sole exception of compound III, where a piperizine ring will avoid folded conformations. With all of the other compounds, repulsion between positively charged nitrogens will most probably lead to extended conformations. However, a single conformer is not expected to occur in solution and, as a consequence of that, several differently oriented structures are expected to be present, their distribution depending on the $\mathrm{pH}$ value of the media. On the basis of our previous studies with bischromophoric analogues, where the presence of excimer emission depends on the $\mathrm{pH}$ and on the chain length, we can conclude that both factors affect chain flexibility and that conformational changes occur upon deprotonation.

Fluorescence decays of the fully protonated species are always fitted with a single exponential (decay time of $24 \mathrm{~ns}$ ). However, as the $\mathrm{pH}$ increases, new monodeprotonated, dideprotonated, etc. species appear with the fluorescence decays translating this fact. For example, in the case of compound $\mathbf{I}$, at $\mathrm{pH}=3$, the major fluorescence emission intensity still arises from the $\mathrm{LH}_{3}$ species (decay time of $24 \mathrm{~ns}$ ), with a small contribution of the $\mathrm{LH}_{2}$ (decay time of $9.5 \mathrm{~ns}$ ) species, whereas at $\mathrm{pH}=6.4$ the fluorescence is essentially from the $\mathrm{LH}_{2}$ species (Figure 1). As a consequence of this, global analysis of the fluorescence decays at the $\mathrm{pH}$ values of 6.4 and 3 (Figure 5) are fitted with the same decay times, 24 and $9.5 \mathrm{~ns}$, with the preexponential factors $\left(a_{i}\right)$ translating the excited-state concentrations (proportional to ground-state concentrations since the extinction coefficient does not change) of $\mathrm{LH}_{3}$ and $\mathrm{LH}_{2}$ species as seen in Figure 1.

The use of the fluorescence decay times of the $\mathrm{LH}_{3}$ and $\mathrm{LH}_{2}$ species allows the determination of $k_{\mathrm{q}}$ for $\mathrm{LH}_{2}$, leading to a quenching rate constant value of $6.4 \times 10^{7} \mathrm{~s}^{-1}$. Comparison can be established with the $8.6 \times 10^{7} \mathrm{~s}^{-1}$ value, obtained from steady-state data, see Table 1.

From the stated above, each species is described by a singleexponential decay, and because we expect conformational flexibility in most of the compounds, if the quenching rate constant are to be dependent on conformation criteria, multiexponential decays were to be expected for each species, unless (A) the interconversion between conformations is slow but the donor/acceptor distances, in all the conformations present in solution, do not appreciably change leading to an identical quenching rate or (B) the interconversion between conformations is fast, and in this case, we are measuring an average electrontransfer rate constant, corresponding to an average of different conformers.

On the other hand, the monoexponential decays for each species could reflect the situation where the quenching rate constant does not depend on the conformation.

The fact that the quenching rate constants and bond distances, for all of the species, correlate within the same exponential dependence also suggests that (i) all the species have similar conformational distributions (or fast interconversion) or (ii) that the mechanism of electron transfer is independent of the conformational distribution, i.e., a through-bond mechanism. Option (i) can be discarded based on our previous study on the kinetics of excimer formation with the bis-chromophoric compounds, ${ }^{19}$ because conformational changes with $\mathrm{pH}$ occur and the excimer formation is slow enough to be measured in our experimental setup. 

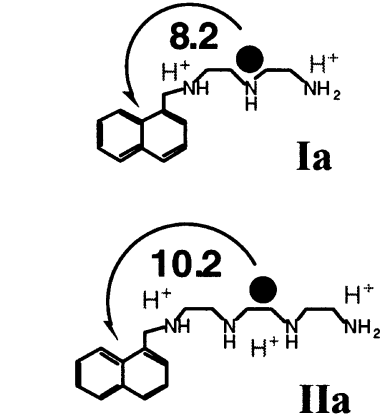

IIa
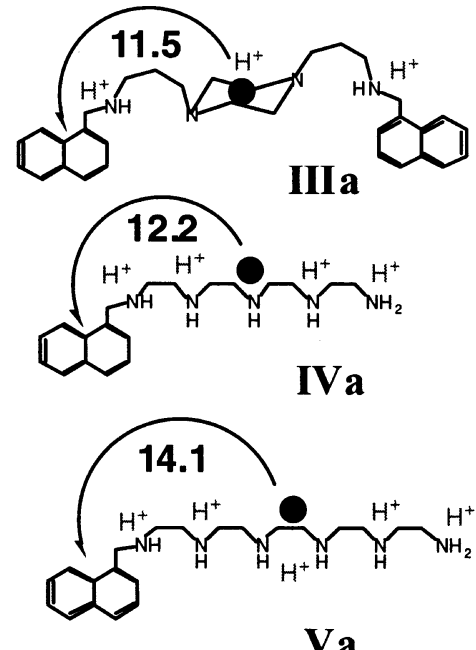

Va

\section{ca. 5}

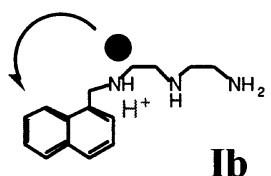

Ib
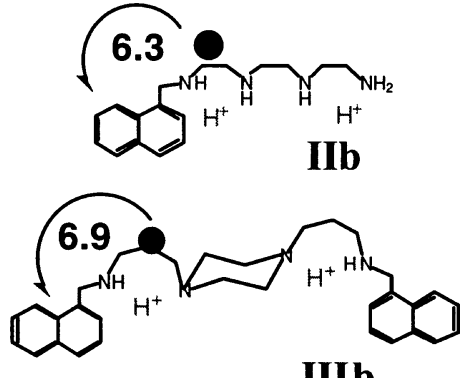

IIIb

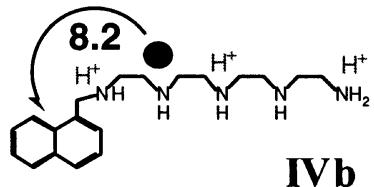

IVb
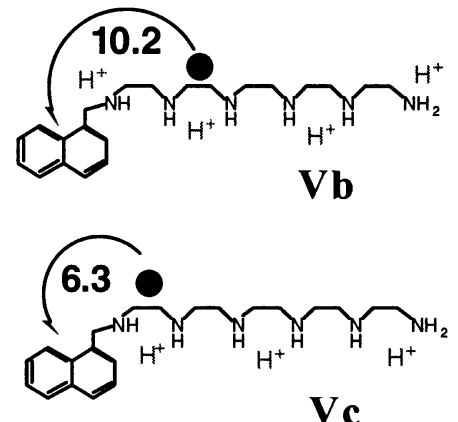

Figure 4. Protonation sequence and distance of the electron transferred in order to follow the exponential dependency reported in Figures 2 and 6.

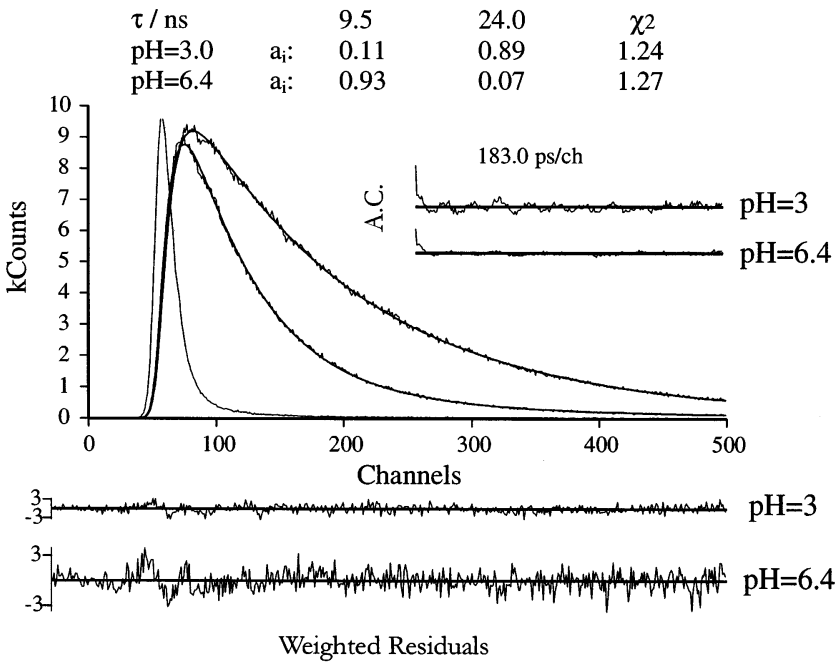

Figure 5. Global analysis of the fluorescence decays of compound I at $\mathrm{pH}=3$ and 6.4 with $\lambda_{\mathrm{exc}}=285 \mathrm{~nm}$ and $\lambda_{\mathrm{em}}=330 \mathrm{~nm}$. Also presented are the weighted residues, autocorrelation functions (A.C.), and $\chi$-squared $\left(\chi^{2}\right)$ values for a better judgment of the quality of the fits.

To account for the role-played by the proton in the electrontransfer process, we have performed identical experiments in deuterated water. The reported results, in Table 1 and Figure 6, show that the quenching rate constants in deuterated water are in average ca. 1.2 times slower than in water $\left(\tau_{0}\right.$ is almost
TABLE 1: Quenching Rate Constants in Water and $d$-Water

\begin{tabular}{lccc}
\hline compound $^{a}$ & $\begin{array}{c}\text { distance } \\
(\AA)\end{array}$ & $\begin{array}{c}k_{\mathrm{q}}\left(\mathrm{s}^{-1}\right) / 10^{7} \\
\left(\mathrm{H}_{2} \mathrm{O}\right)\end{array}$ & $\begin{array}{c}k_{\mathrm{q}}\left(\mathrm{s}^{-1}\right) / 10^{7} \\
\left(\mathrm{D}_{2} \mathrm{O}\right)\end{array}$ \\
\hline Ia & 8.2 & 8.6 & 6.7 \\
IIa & 10.2 & 2.6 & 1.8 \\
IIIa & 11.5 & 1.7 & 1.0 \\
IVa & 12.2 & 1.3 & 0.87 \\
Va & 14.1 & 0.6 & 0.27 \\
Ib & $b$ & 35 & 50 \\
IIb & 6.25 & 19 & 8.1 \\
IIIb & 6.9 & 17 & 12 \\
IVb & 8.2 & 7 & 4.2 \\
Vb & 10.2 & 3.8 & 2.8 \\
Vc & 6.25 & 20 & 14
\end{tabular}

${ }^{a}$ See Figure 2 for the protonation sequence. ${ }^{b}$ In this compound, the distance lies between the first nitrogen $4.3 \AA$ and the middle distance between the $\mathrm{N}(1)$ and $\mathrm{N}(2)$ nitrogens, $6.25 \AA$.

identical to water; $25 \mathrm{~ns}$ ). This result suggests isotope sensitivity compatible with an association electron-proton (deuteron) transfer. The dependence with the distance is, however, similar in both media: deuterated water, $\beta=0.49 \AA^{-1}$, and water, $\beta$ $=0.45 \AA^{-1}$.

The use of classical and quantum mechanical models to account for the electron transfer phenomenon, in particular their dependence with the distance, is not a simple task. This is true essentially because the series in question lack homogeneity, in the sense that there is no evidence to support that the driving 


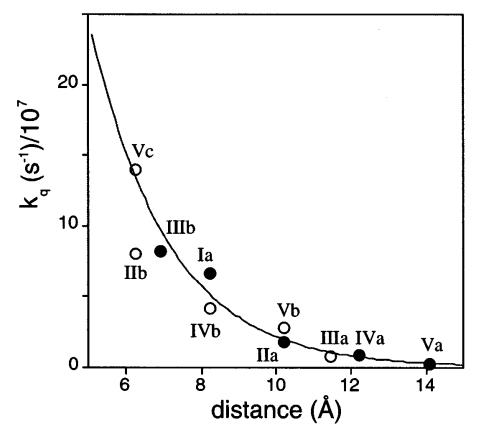

Figure 6. Exponential dependence of the quenching rate constants with the distance in deuterated water. Closed circles, monodeprotonated species; open circles, dideprotonated (and trideprotonated) species.

force for the electron-transfer process, $\Delta G^{\circ}$, and the energy required to reorganize nuclear coordinates upon electron transfer, $\lambda$, is the same when the nitrogen is completely deprotonated (as in the case of species 2 and 5 or 9 in Figure 4) or when it shares a proton with an adjacent nitrogen (as in the other cases). At this point in our studies, we can only look to the observed exponential dependence as a trend here expressed by an empirical law. However, despite these limitations, some aspects merit our attention. Independently of the exact meaning of the $\beta$ factor, it should reflect how the electron-transfer process falls off with the distance. Some comparisons can be made with other covalently linked bridged redox centers. Typical values for this parameter are found to be $\beta=0.9,{ }^{20} 1.01,{ }^{7} 0.85,{ }^{21}$ and $0.5^{22}$ $\AA^{-1}$ and tunneling through vacuum $(\beta=$ from 2.8 to 3.5 $\left.\AA^{-1}\right) .{ }^{23,24}$ According to Page and co-workers in the case of the electron tunneling in biological oxidation-reduction systems, a $\beta$ value of $0.9 \AA^{-1}$ corresponds to a fully packed medium, whereas $\beta=2.8 \AA^{-1}$ corresponds to the interstitial space in the protein structure outside the united van der Waals atomic radii. ${ }^{25}$ These authors have also suggested an intermediate value ( $\beta=1.4 \AA^{-1}$ ), for the electron-transfer process occurring in proteins.

The values of $\beta$, reported in the present work, are quite low and very similar to those found by Michel-Beyerle and co-workers, for the preexponential factors of the rate constants in CLDA systems where a pyrene electron acceptor is linked to a dimethylaniline electron donor through a bridge consisting in two terminal methylene groups and different central aromatic fragments. ${ }^{21}$ In their case, the small value of the $\beta$ factor was attributed to the presence of aromatic groups in the bridge unit.

In our case, the dependence of the quenching rate constants on isotopic substitution suggest that proton movement is involved in the controlling step of electron transfer. In that case, a possible interpretation for the distance dependence is that the quenching rate constant is reflecting the time it takes to deprotonate the nitrogen nearest to the naphthalene moiety, i.e., proton migration through bond. This would also account the fact that conformational changes upon deprotonation are not reflected on the quenching mechanism.

\section{Summary/Conclusions}

Electron transfer processes occurring in a new family of compounds have been discussed. This is shown to be distance and $\mathrm{pH}$ dependent. The acceptor unit consists of a naphthalene chromophore, and the donor unit consists of a polyaminic chain. Different size chains were considered. An exponential dependence of the chain distance (measured from the electron donor site in the polyamine chain to the closest carbon of the naphthalene unit) with the quenching rate constant was found.
In the present case, the particularity of depending on the hydrogenionic concentration of the media is merely a consequence of the deprotonation site in the polyamine chain from where electron transfer takes place. In these systems, the role of the proton, in the electron-transfer process, cannot be neglected as attested by the different values obtained for the electron-transfer quenching rate constant in water and deuterated water.

Acknowledgment. Financial support from Fundação para a Ciência e Tecnologia Project 32442/99 (Portugal), PRAXIS/ QUI/10137/98, HPRN-CT-2000-29 (EC), and DGICYT Project BQU2000-1424 (Spain) is gratefully acknowledged. M.T.A. and P.D. thank Generalitat Valenciana and Ministerio de Ciencia y Tecnología for their respective $\mathrm{PhD}$ grants.

\section{References and Notes}

(1) Balzani, V.; Scandola, F. Supramolecular Photochemistry; Ellis Horwood, Chichester, U.K., 1991; Chapter 5.

(2) Salemme, F. R.; Chance, B.; de Vault, D. C.; Frauenfelder, H.; Marcus, R. A.; Schirieffer, J. R.; Sutin, N. Tunneling in biological systems; Academic Press: New York, 1979.

(3) Michel-Beyerle, M. E. Antennas and reaction centers in photosynthetic bacteria; Springer: New York, 1985.

(4) Breton, J.; Vermeglio, H. The photosynthetic bacterial reaction center-structure and dynamics; Plenum Press: New York, 1988.

(5) Gloss, G. L.; Miller, J. R. Science 1988, 240, 440.

(6) Miller, J. R.; Calcaterra, L. T.; Gloss, G. L. J. Am. Chem. Soc. 1984, 106, 3047.

(7) Gloss, G. L.; Calcaterra, L. T.; Green, N. J.; Penfield, K. W.; Miller, J. R. J. Phys. Chem. 1986, 90, 3637.

(8) Simon, J. A.; Curry, S. L.; Schmehl, R. H.; Schatz, T. R.; Piotrowiak, P.; Jin, X.; Thummel, R. P. J. Am. Chem. Soc. 1997, 119, 11012.

(9) Pina, F.; Bernardo, M. A.; García-España, E. Eur. J. Inorg. Chem. 2000, 2143

(10) Albelda, M. T.; Bernardo, M. A.; Díaz, P.; García-España, E.; de Melo, J. S.; Pina, F.; Soriano, C.; Luis, S. V. Chem. Comum. 2001, 1520.

(11) Alves, S.; Pina, F.; Albelda, M. T.; García-España, E.; Soriano, C.; Luis, S. Eur. J. Inorg. Chem. 2001, 405.

(12) García-España, E.; Ballester, M. J.; Lloret, F.; Moratal, J. M.; Faus, J.; Bianchi, A. J. Chem. Soc., Dalton Trans. 1998, 101.

(13) Fontanelli, M.; Micheloni, M. Proceedings of the I Spanish-Italian Congress on Thermodynamics of Metal Complexes; Diputación de Castellón: Spain, 1990

(14) Gran, G. Analyst (London) 1952, 77, 881. Rossotti, F. J., Rossotti, H. J. Chem. Educ. 1965, 42, 375.

(15) Sabatini, A.; Vaca, A., Gans, A. Coord. Chem. Rev. 1992, 120, 389.

(16) Convington, A. K.; Paabo, M.; Robinson, R. A.; Bates, R. G. Anal. Chem. 1968, 40, 700.

(17) Bernardo, M. A.; Alves, S.; Pina, F.; Seixas de Melo, J.; Albelda, J. M. T.; Garcia-España, E.; Llinares, J. M.; Soriano, C.; Luis, S. V. Supramol. Chem. 2001, 13, 435.

(18) (a) Striker, G.; Subramaniam, V.; Seidel, C. A. M.; Volkmer, A. J. Phys. Chem. B 1999, 103, 8612. (b) Goldenberg, M.; Emert, J.; Morawez, H. J. Am. Chem. Soc. 1978, 100, 7171.

(19) Seixas de Melo, J.; Albelda, M. T.; Díaz, P.; García-España, E.; Lodeiro, C.; Alves, S.; Lima, J. C.; Pina, F.; Soriano, C. J. Chem. Soc., Perkin Trans. 2 2002, 991.

(20) Smalley, J. F.; Feldberg, S. W.; Chidsey, C. E. D.; Linford, M R.; Newton, M. D.; Liu, Y.-P. J. Phys. Chem. 1995, 99, 13141.

(21) Finckh, P.; Heitele, H.; Volk, M.; Michele-Beyerle, M. E. J. Phys. Chem. 1988, 92, 6584.

(22) Oevering, H.; Paddon-Row, M. N.; Heppener, M.; Olivier, A. M.; Cotsaris, E.; Verhoeven, J. W.; Hush, N. S. J. Am. Chem. Soc. 1987, 109, 3258.

(23) Moser, C. C.; Keske, J. M.; Warncke, K.; Farid, R. S.; Dutton, P. L. Nature 1992, 355, 796.

(24) Beratan, D. N.; Onuchic, J. N.; Winkler, J. R.; Gray, H. B. Science 1992, 258, 1740.

(25) Page, C. C.; Moser, C. C.; Chen, X.; Dutton, P. L. Nature 1999 402,47 